\title{
Re-descriptions of Isospora ameivae Carini, 1932 in the Teiid Lizard Ameiva ameiva and Isospora hemidactyli Carini, 1936 in the Gecko Hemidactylus mabouia, with Particular Reference to their Endogenous Stages
}

\author{
R Lainson/ ${ }^{+}$, I Paperna* \\ Departamento de Parasitologia, Instituto Evandro Chagas, Caixa Postal 1128, 66090-000 Belém , PA, Brasil \\ *Department of Animal Sciences, Faculty of Agriculture, Hebrew University of Jerusalem, Rehovot 76-100, \\ Israel
}

Redescriptions are given of the mature oocysts of Isospora ameivae Carini, 1932, from the teiid lizard Ameiva ameiva, and Isospora hemidactyli Carini, 1936 from the gecko Hemidactylus mabouia, in north Brazil. The endogenous stages of the two parasites in the small intestine are described. Those of I. ameivae are intracytoplasmic, whereas those of I. hemidactyli are intranuclear.

Key words: Hemidactylus mabouia - Ameiva ameiva - lizards - Isospora hemidactyli - Isospora ameivae endogenous stages - Brazil

As far as we can ascertain, 47 named species of Isospora have been recorded in lacertilian hosts (Levine 1988, Matuschka 1989, Upton et al. 1991a,b, 1992, Bui et al. 1992, Finkelman \& Paperna 1994a,b,1995, Cisper et al. 1995, Modrý \& Koudela 1995, Modrý et al. 1997), and most descriptions of these have been based only on the morphology of the oocysts and sporocysts. Studies by various authors on the endogenous stages of at least 17 species, however, have indicated that the parasites of lacertilians with oocysts of isosporan morphology are divisible into two distinct groups: those whose endogenous stages are intranuclear, and those whose development is in the host cell cytoplasm (Else \& Colley 1975, Rogier \& Colley 1976, Atkinson \& Ayala 1987, Finkelman \& Paperna 1994a,b for review and new descriptions, Modrý \& Koudela 1995, El-Toukhy et al.1996).

Carini (1932) gave the name Isospora ameivae to oocysts he described in faeces from the teiid lizard Ameiva ameiva from Salto de Itu, State of São Paulo, Brazil, and development was said to be in the gut epithelium. In 1936 he named another isosporan, Isospora hemidactyli, in faeces from

Work supported by a grant from the Wellcome Trust, London (RL).

${ }^{+}$Corresponding author. Fax: + 55-91-226.1284.

Received 28 December 1998

Accepted 18 March 1999 the house-gecko Hemidactylus mabouia, and his figures suggested merogony and gametogeny to be within the cytoplasm of the epithelial cells of the small intestine (Carini 1936)

During our studies on some other coccidial parasites of A. ameiva and H. mabouia from Capanema and Belém, north Brazil (Lainson \& Paperna 1999), we found some of these lizards to be passing oocysts which, on sporulation, were considered as conspecific with I. ameivae and I. hemidactyli. The examination of further lizards has enabled the following redescriptions of these two parasites and provided new morphological data regarding the exogenous and endogenous stages. The development of I. ameivae is intracytoplasmic, whereas that of I. hemidactyli is intranuclear and not intracytoplasmic as first described.

\section{MATERIALS AND METHODS}

On capture, each lizard was housed in a separate plastic cage. A pledge of wet cotton-wool in a Petri-dish provided water, and the animals were fed with adult and larval stages of the flour beetle, Tenebrio molitor. Collected faecal material from each animal was gently triturated in $2 \%(\mathrm{w} / \mathrm{v})$ aqueous potassium dichromate solution $\left(\mathrm{K}_{2} \mathrm{Cr}_{2} \mathrm{O}_{7}\right)$ and maintained as a thin layer in a covered Petri-dish kept at room temperature (approximately $23-24^{\circ} \mathrm{C}$ ). Presence of isosporan oocysts was established both by direct microscopy and following flotation by zinc sulphate solution (sp.gr. 1.18).

Mixed infection with species of Eimeria, Acroeimeria and Choleoeimeria were common (Lainson \& Paperna 1999). For this reason, liz- 
ards showing only oocysts of I. ameivae or $I$. hemidactyli in the first flotation were examined by this method again when further faecal material was available (the interval varying from 5 to 10 days). If still with no concomitant coccidial infection, the animals were sacrificed after a further 6 days, when faecal material was removed from the rectum for a final examination and the intestine searched for endogenous stages. Oocysts and sporocysts were measured by normal light microscopy, using a $\mathrm{x}$ 100 neofluar objective, $x 10$ eyepieces and an ocular micrometer. Photomicrographs were prepared with a Zeiss Photomicroscope III and Kodak TMX 100 film. All measurements are in $\mu \mathrm{m}$ and are given as means, followed by the range in parentheses and the shape-index (ratio of length/width). Location of endogenous stages was by microscopic examination of fresh coverslip preparations of gut epithelium scrapings at intervals along the intestine. Thin smears of scrapings from the developmental areas were air-dried and either fixed in absolute methyl alcohol or in aqueous Bouin's fluid. Methyl alcohol fixed smears were stained for one hour by Giemsa's method (36 drops of stain to 15 $\mathrm{ml}$ distilled water buffered to $\mathrm{pH}$ 7.4). Those fixed in Bouin's fluid were washed in 70\% ethyl alcohol until colourless, rinsed briefly in tap water, stained for $1.5 \mathrm{hr}$ in Giemsa, dehydrated and differentiated in graded mixtures of acetone/xylol (95:5 down to pure xylol) and mounted in 'Permount' (Fisher Scientific). Portions of intestine with developmental stages were fixed in $10 \%$ neutral buffered formalin and embedded in paraffin wax. Histological sections were cut at $4 \mu \mathrm{m}$ and stained with haematoxylin and eosin.

\section{RESULTS}

Redescription of Isospora ameivae Carini, 1932 (Figs 1-26; 49)

Redescription of the oocyst (Figs 1-3; 49): mature forms (50 measured) $17.2 \times 15$ (15.5-18.5 x 14.1-15.5), shape-index 1.1 (1-1.2), subspherical. Oocyst wall a single, colourless layer about 0.6 thick, without micropyle or striations, and which may crumple around the sporocysts. No oocyst residuum, but a spherical polar body measuring $3 \mathrm{x}$ 3 - 3.7 x 3.7 is constantly present: initially it appears as a structureless, refractile body but assumes a more granular aspect with age (especially after flotation in $\mathrm{ZnSO}_{4}$ ). Sporocysts (50 measured) are pear-shaped, $12.1 \times 7.5$ (11.8-13.3 x 7.4-8.1), shape-index 1.6 (1.6-1.7). The Stieda body, if it can be referred to as such, is represented by a very inconspicuous thickening of the sporocyst wall at the narrower end: there is no sub-Stieda body. A bulky sporocyst residuum is composed of fine granules and some larger spherules. As far as as- certained, there is at least one refractile body in the sporozoites, situated posterior to the nucleus. Endogenous stages (Figs 4-26): merogony and gametogony occur within the cytoplasm, at the distal end of the epithelial cells of the small intestine. In Giemsa stained smears the smallest undivided forms seen (future meronts or gamonts) measured 3.7-4.4 x 2.2-3.7. Binucleate meronts were approximately $4.4 \times 3.7$, while the largest undivided form encountered was 15 x 16 and contained approximately 40 nuclei. Most of the asexual stages are spherical to broadly ellipsoidal in shape, with the vacuolated cytoplasm staining a deep, bright blue and frequently containing small, scattered, deep red granules. The nuclei, which are rather irregular, diffuse bodies, contain a small number of more densely staining granules and are quite unlike those of the developing microgamonts. The number of merozoites produced is highly variable, ranging from 6 to approximately 40. The usual number seen, however, is between 6-20. The impression gained was that two types of meronts are produced, one giving rise to merozoites measuring approximately 7-8 x 2 (Figs 8, 9), and another producing smaller merozoites which are only approximately 6-7 x 1 (Figs 10, 11). In Giemsa stained material, and in common with other eimeriids, even the youngest microgamonts are readily distinguished from meronts by the uniformity of their densely stained nuclei, which are frequently angular in shape and periferally disposed. The cytoplasm is virtually without vacuoles and stains an even violet-blue. Binucleate forms measured $4 \times 4$, but with growth the parasites tend to become ellipsoidal in shape, reaching up to $24 \times 16$ and containing a large number of nuclei. Fully mature microgamonts are of approximately the same size and shed a variable number of flagellated, comma-shaped microgametes (sometimes over 100) measuring about $4 \times 1$ : there remains a bulky cytoplasmic residuum. Young macrogamonts measuring only from 4-7 in diameter are distinguished by the early appearance of a number of larger vacuoles in the cytoplasm, which stains a delicate, light blue: the nucleus is large, diffuse and granular, and a karyosome is sometimes visible. In dab-smears, apparently mature macrogamonts are spherical to sub-spherical and measure from $13 \times 13$ to $17 \times 16.3$. The cytoplasm is uniformly highly vacuolated, stains a bright blue and contains a large number of granules of variable size which stain a deep red: the nucleus contains a large and densely stained karyosome. The mean measurement of zygotes, or young oocysts, is $16 \times 15$ : their cytoplasm stains a deep grey-blue and the wall-forming bodies are seen, for the first time, as small darker staining bodies 

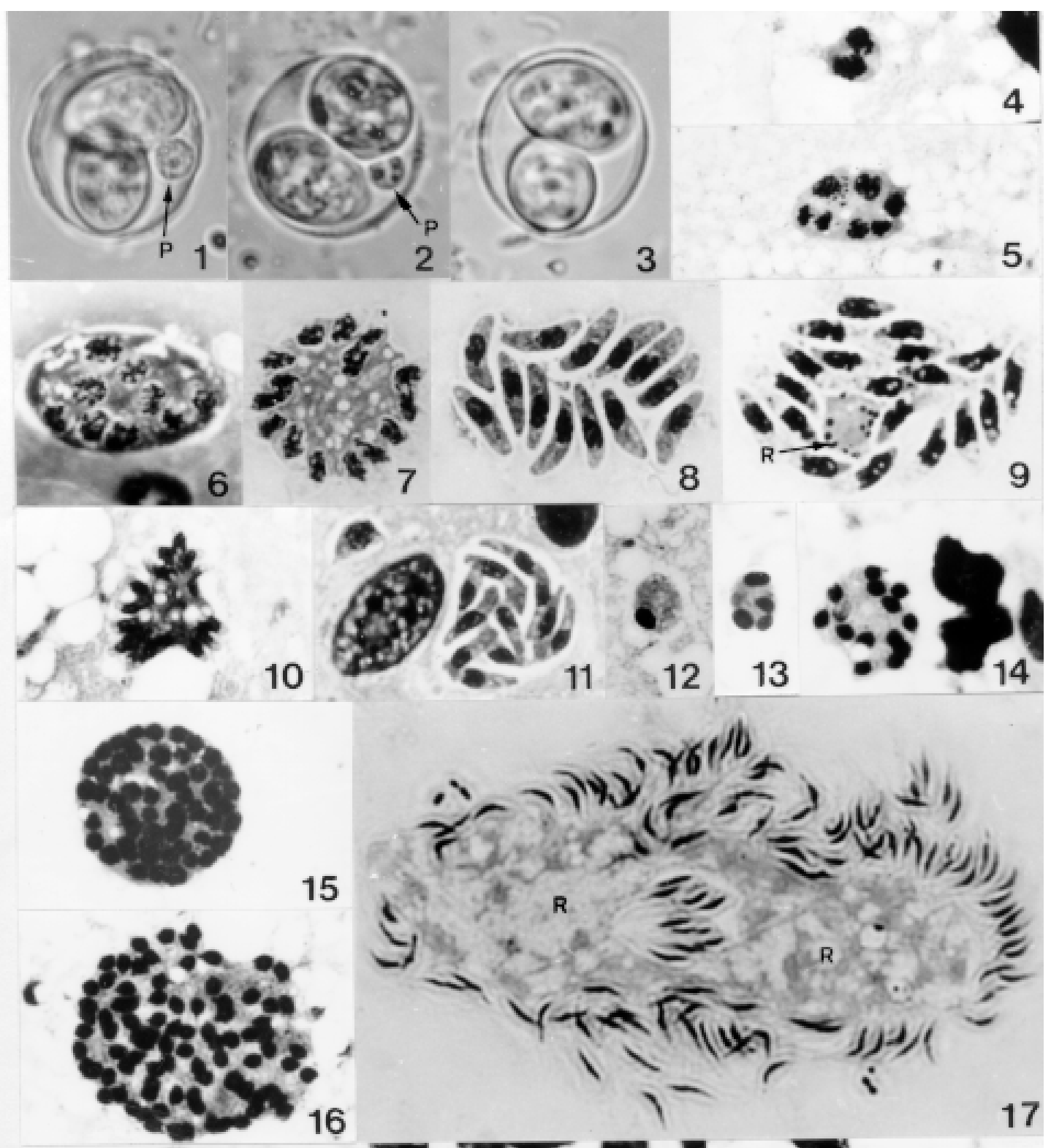

15
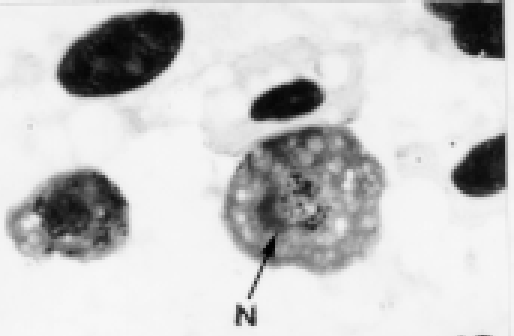

18
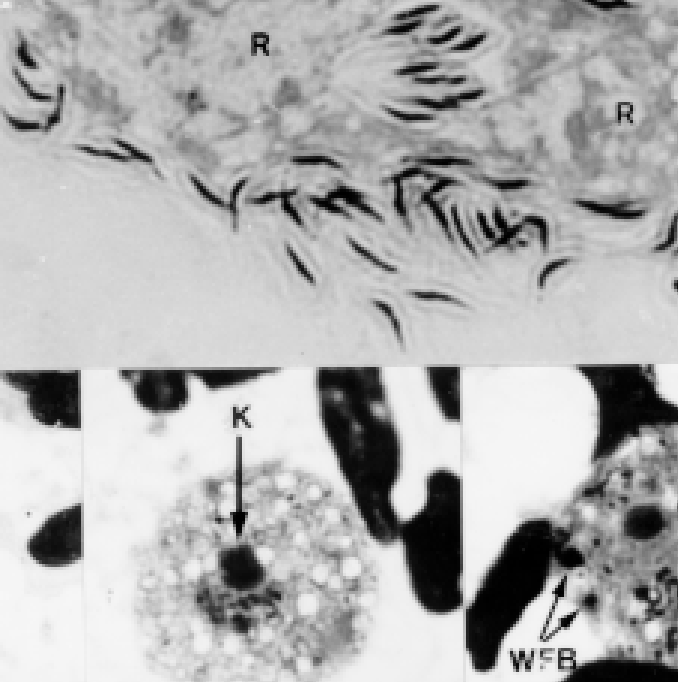

19

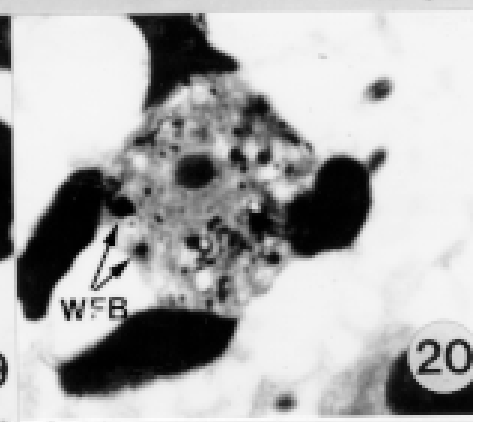

Isospora ameivae in the teiid lizard Ameiva a. ameiva. Figs 1-3: mature oocysts: $\mathrm{P}=$ polar body. Figs 4-20: endogenous steges as seen in Giemsa-stained smears of epithelial scrapings from the small intestine. Figs 4-11: developing meronts producting large merozoites (Figs 8, 9) and small merozoites (Figs 10,11). Figs 12-16: developing microgamonts. Fig. 17: mature microgamont shedding microgametes. Fig. 18: two young macrogamonts. Fig. 19: mature macrogamont. Fig. 20: zygote. K= karyosome; $\mathrm{N}=$ nucleus; $\mathrm{R}=$ residual cytoplasm; $\mathrm{WFB}=$ large wall-forming bodies. $\mathrm{Bar}=10 \mu \mathrm{m}$. 


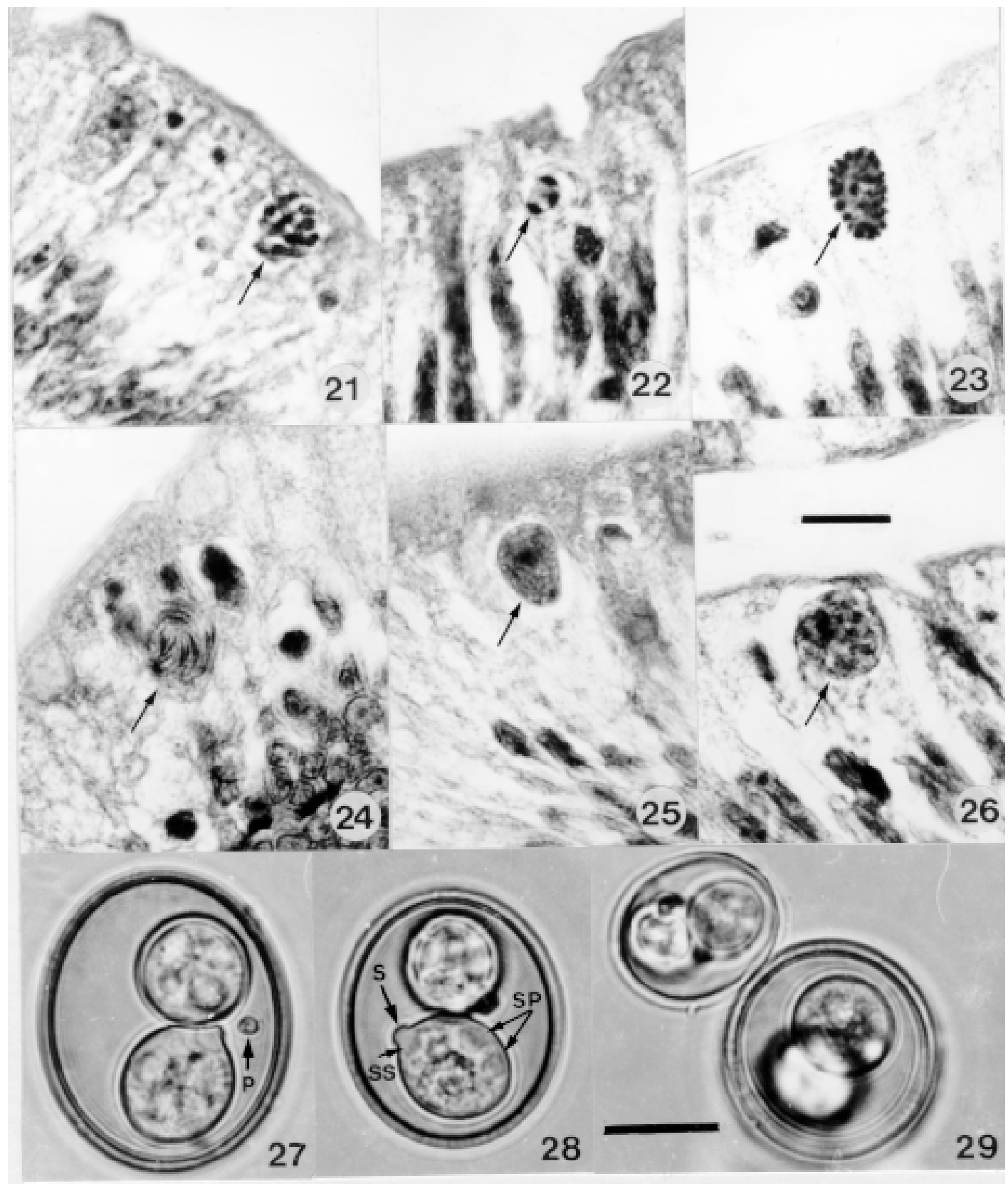

Isospora ameivae in histological sections of the small intestine of the lizard Ameiva a. ameiva, showing the intracytoplasmic development of the parasite (arrowed) in the distal portion of the epithelial cells. Fig. 21: mature meront with merozoites. Fig. 22: young microgamont with 3 nuclei. Fig. 23: almost mature microgamont, with peripherally disposed nuclei. Fig. 24: mature microgamont, shedding microgametes. Fig. 25: macrogamont. Fig. 26: zygote (or young oocyst). Haematoxylin \& eosin. Bar $=10 \mu \mathrm{m}$. Isospora hemidactyli in the gecko Hemidactylus mabouia. Figs 27-29: mature oocysts. Fig. 29 indicates the wide size range of both the oocyst and the sporocysts. $\mathrm{P}=$ polar body; S = Stieda body; SS $=$ sub-Stieda body $; \mathrm{SP}=$ sporozoites. $\mathrm{Bar}=10 \mu \mathrm{m}$. 
with rather poorly defined outlines. The nucleus has a large, heavily stained karyosome.

Host: Ameiva ameiva (Linnaeus) (Reptilia: Teiidae).

Locality: Carini's infected lizards were from Salto de Itu, State of São Paulo, south Brazil, Those of the present study were from Capanema, State of Pará, north Brazil.

Sporulation: exogenous. The exact time is uncertain, but the majority of the oocysts were mature after $24 \mathrm{hr}$ outside the host.

Prevalence: of 17 specimens examined, 12 (70.6\%) were infected with I. ameivae. Concomitant infection with species of Acroeimeria and Choleoeimeria were frequent (Lainson \& Paperna 1999). Pathogenicity: apparently none. The presence of the parasite is not accompanied by any notable pathology in the small intestine.

\section{Redescription of Isospora hemidactyli Carini, 1936 (Figs 27-47; 48)}

Redescription of the oocyst (Figs 27-30; 48): mature forms (50 measured) 21 x 19.2 (16.2-27 x 1423), shape-index 1.1 (1-1.4), predominantly subspherical to broadly ellipsoidal, rarely spherical. Oocyst wall a single, smooth, colourless layer about 1.25 thick, with no micropyle: faintly striated. No oocyst residuum, but with the frequent presence of a spherical to broadly ellipsoidal polar body of approximately $1-2$. Sporocysts (50 measured) 11 x 8.8 (8.7-11 x 7.5-10), shape-index 1.2 (1.1-1.5), broadly ellipsoidal, with a nipple-like Stieda body and a conspicuous sub-Stieda body. The sporozoites are recurved around a bulky residuum composed of fine granules intermixed with larger spherules. They possess at least one refractile body, posterior to the nucleus.

Endogenous stages (Figs 31-47): merogony and gametogony is within the nucleus of the epithelial cells of the small intestine. In some cases, the host cell nucleus containing the parasite may become greatly hypertrophied, while in others, notably those containing the microgamonts, it is reduced to a fine membrane. In Giemsa stained smears the smallest undivided forms seen (future meronts or gamonts) were spherical and measured from 4-5. The only advanced merogonic stage detected in smears measured $20 \times 20$, contained approximately 60 irregular and diffusely stained nuclei and was surrounded by a relatively thick band of the host cell nuclear material. No asexual forms were found in histological sections. Developing microgamonts are distinguished by their small, compact and densely staining nuclei arranged on the surface of the parasite. The host-cell nucleus seems most frequently to be reduced to a fine membrane around the parasite, unlike the thicker nuclear residuum surrounding most of the macrogamonts and zygotes. The only intact, mature microgamont seen in the stained smears was a perfect, broad ellipsoid measuring $19 \times 15$ and containing a large number of comma-shaped microgametes. In sections, most of the mature microgamonts are in similar shape. Occasional larger, elongated forms are probably disintegrating during the shedding of microgametes. After this process there remains a cytoplasmic residuum, which may be compacted or dispersed. The development of the macrogamont calls for no particular comment. The densely staining cytoplasm is very finely vacuolated and with a number of deep red granules of variable size: the nucleus contains a prominent karyosome. In sections the zygotes or young oocysts are at first elongated, doubtless due to pressure from the neighbouring host cell nuclei, but with migration to the epithelial surface they assume the broadly ellipsoidal shape which is to be that of the mature oocyst.

Host: Hemidactylus mabouia (Moreau de Jonnès, 1818) (Reptilia: Gekkonidae).

Locality: the infected geckos examined by Carini (1936) were from the State of São Paulo, south Brazil. Those of the present study were from Capanema and Belém, State of Pará, north Brazil. Sporulation: exogenous. The exact time is uncertain, but the majority of the oocysts were mature after $24 \mathrm{hr}$ outside the host.

Prevalence: of 11 geckos examined, 7 (63.6\%) were infected. Concomitant infections occurred with Eimeria boveroi Carini \& Pinto, 1930 (3); Choleoeimeria rochalimai (Carini \& Pinto, 1926) Lainson \& Paperna, 1998 (1) and with both $E$. boveroi and $C$. rochalimai (1). Two geckos showed only oocysts of $I$. hemidactyli in their faeces after repeated flotation concentration.

Pathology: heavily infected geckos showed no outward signs of infection and histological sections of the infected gut showed no notable pathology.

\section{DISCUSSION}

The hazards of identifying some eimerian coccidians solely by the morphology of their oocysts and sporocysts has been discussed by numerous authors (Finkelman \& Paperna 1994 for review), and species of Isospora sensu lato are no exception. Thus, the oocysts of I. amphiboluri Cannon, 1967 and I. cannoni Finkelman \& Paperna, 1994, both in Australian lizards, are sufficiently similar to be easily confused. The endogenous stages of the former, however, are in the cytoplasm of the host cell whereas those of the latter are intranuclear.

It is customary to give the name of Isospora to all those intestinal coccidia possessing oocysts with 

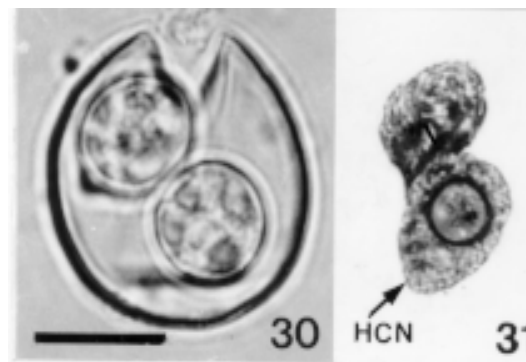

31
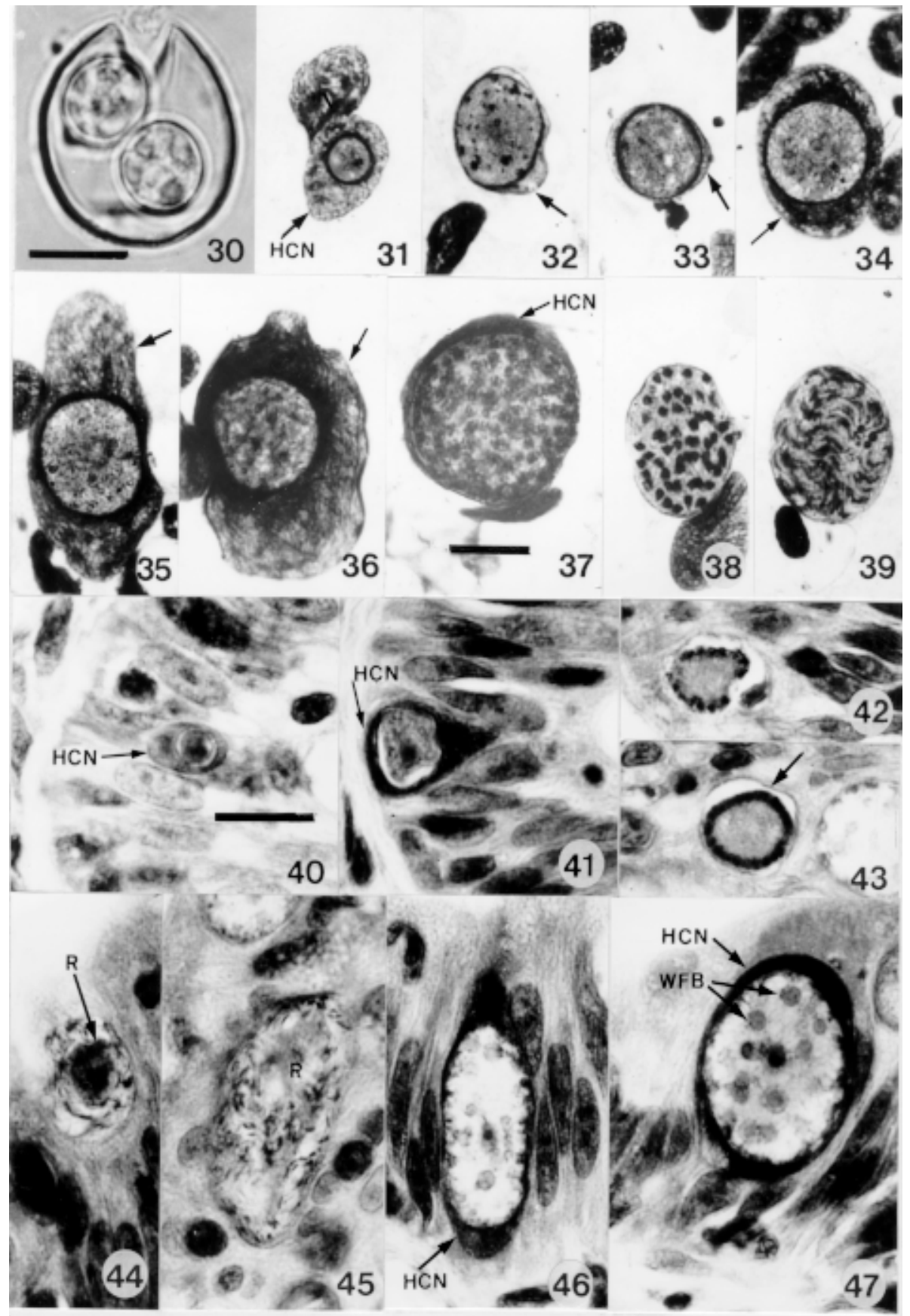

Isospora hemidactyli in the gecko Hemidactylus mabouia. Fig. 30: a crushed, mature oocyst, showing the wall to be of a single layer. Bar $=10 \mu \mathrm{m}$. Figs 31-39: endogenous stages as seen in Giemsa-stained smears of scrapings from the epithelium of the small intestine. Fig. 31: young macrogamont within the host-cell nucleus. Figs 32-36: macrogamonts: in Figs 32-33 the host-cell nucleus has been reduced to a fine membrane around the parasites, while in Figs 34-36 it is greatly hypertropied (arrows). Fig. 37 : an almost mature meront. Fig 38: an almost mature microgamont. Fig. 39: a mature microgamont shedding a large number of microgametes: the host-cell nucleus is reduced to a very fine, cyst-like membrane. Figs 40-47: gametogony as seen in sections of the small intestine. Figs 40-41: intranuclear, developing macrogamonts. Figs 42-43: developing microgamonts, with peripherally disposed nuclei: the host-cell nucleus has been reduced to a cyst-like membrane (arrow). Figs 44-45: mature microgamonts, shedding microgametes. Figs 46-47: zygotes (or young oocysts). Haematoxylin and eosin. Bar $=10 \mu . \mathrm{HCN}=$ host-cell nucleus; $\mathrm{R}=$ residual cytoplasm; WFB = large wall-forming bodies . 


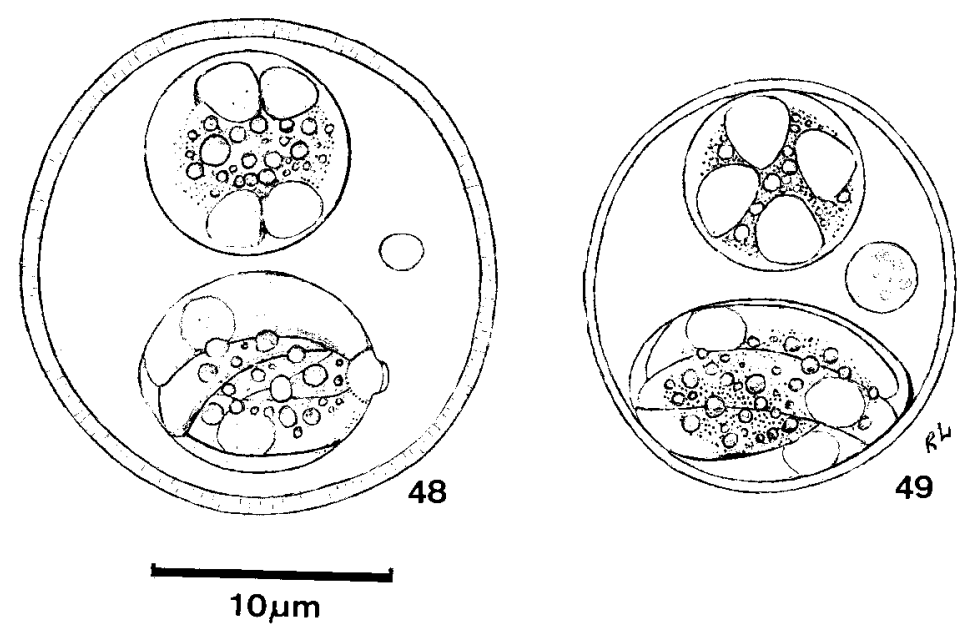

Line drawings of the mature oocysts of Isospora hemidactyli (Fig. 48) and Isospora ameivae (Fig. 49).

two sporocysts, each containing four sporozoites, and which are passed unsporulated in the faeces regardless of their natural division into two distinct groups with either intracytoplasmic or intranuclear development of the endogenous stages. However, peculiarities in the endogenous development of some reptilian coccidians previously included in the genus Eimeria by virtue of their similar oocyst morphology, have led to their reallocation to the genera Choleoeimeria and Acroeimeria by some authors (Paperna \& Landsberg 1989). It might be argued, therefore, that similar recourse should be taken to separate the isosporan parasites, based on the intranuclear or intracytoplasmic development of their endogenous stages. So far, species of Choleoeimeria and Acroeimeria have been recorded only in reptiles, and all have tetrasporocystic, dizoic oocysts. On the other hand, intranuclear development is known to occur in parasites with the oocystic morphology of Cyclospora, Eimeria, Goussia and Isospora: in fish (Eimeria s.l. and Goussia), amphibians (Eimeria and Isospora) and mammals (Eimeria and Cyclospora) (Noller 1923, Davis et al. 1957, Lom \& Dykovà 1982, Mohamed \& Molyneux 1990). Assignment of a new generic name to intranuclear isosporans (s.l.) of reptiles on this criterion alone would, therefore, necessitate considerable taxonomic revision within several genera of the Eimeriidae, and is best delayed until more information is available regarding the intranuclear coccidians as a whole.

H. mabouia is a widely distributed gecko, found in Africa south of $10^{\circ} \mathrm{N}$, the Antilles (principally the Lesser Antilles - type locality St. Vincent Island), Madagascar, and South America. It occurs along the coastal region of Brazil and the Guianas, along most of the Amazon river, its head-waters in Peru, Ecuador, and some localities in Central Brazil. The southern limit of the species is probably Rio Grande do Sul (Avila Pires 1995).

The general opinion is that this gecko was transported from Africa to the Americas during the slave trade, although its arrival there could be by way of floating débris. Throughout its distribution it is essentially 'domesticated' and predominantly found in and around human dwelling places. In spite of this wide distribution of its host, we are unaware of studies on I. hemidactyli other than those of Carini (1936) and the present observations, and it would be interesting to see if the same parasite occurs in H. mabouia throughout its geographic range, particularly in the Old World. There are approximately 70-80 other species of Hemidactylus, mostly outside the Neotropics, but the only description of Isospora in one of these appears to be that of $I$. knowlesi in H. flaviviridis from India (Ray \& Das Gupta 1937). This parasite differs from I. hemidactyli in its intracytoplasmic development within the epithelial cells of the intestine, once again emphasising the importance of the endogenous stages when identifying coccidians with morphologically similar oocysts.

There are 20 recognized species of Ameiva, and the genus is widely distributed in Mexico, Central and South America and the Antilles: subspecies, widely accepted in the past, are not accepted by more recent herpetologists (Avila Pires 1995). Information on the presence and taxonomic status of Isospora in these lizards, based both on the oocysts and endogenous stages of the parasites, would be of considerable interest. To date, the only record appears to be I. ameiva in Ameiva ameiva in Brazil, by Carini (1936) and the present authors. 


\section{ACKNOWLEDGEMENTS}

To Constância M Franco and Manoel C de Souza for technical assistance and Walter M Campos for the preparation of the histological sections.

\section{REFERENCES}

Atkinson CT, Ayala SC 1987. Isospora manchacensis n.sp., an intranuclear coccidian from the Louisiana ground skink, Scincella lateralis (Say, 1823) (Lacertilia:Scincidae). J Parasitol 73: 817-823.

Avila Pires TCS 1995. Lizards of Brazilian Amazonia (Reptilia: Squamata), Zoologische Verhandelingen, Nationaal Natuurhistorisch Museum, Leiden, 706 pp.

Bui HT, Powell R, Smith DD, Parmerlee JS, Lathrop A 1992. A new coccidian (Apicomplexa: Eimeriorina) from Anolis distichus (Sauria: Polychridae) in the Dominican Republic. J Parasitol 78: 784-785.

Cannon LRG 1967. New coccidia from Australian lizards. Parasitology 57: 227-235.

Carini A 1932. Isospora ameivae n.sp. e outras coccideas parasitas de um lagarto do Brasil, p. 921-923, 7ㄹ Reun. Soc. Arg. Patol. Reg. del Norte Tucumán.

Carini A 1936. Sur une Isospora de l'intestin de l'Hemidactylus mabujae. Ann Parasit Hum Comp 14: 444-446.

Christensen JF 1941. The oocysts of coccidia from domestic cattle in Alabama (U.S.A), with descriptions of two new species. J Parasitol 27: 203-220.

Cisper GL, Huntington C, Smith DD, Powell R, Parmerlee JS, Lathrop A 1995. Four new coccidia (Apicomplexa: Eimeriidae) from anoles (Lacertilia: Polychrotidae) in the Dominican Republic. $J$ Parasitol 81: 252-255.

Davis LR, Bowman GW, Boughton DC 1957. The endogenous development of Eimeria alabamensis Christensen 1941, an intranuclear coccidium of cattle. J Protozool 4: 225-229.

Else JG, Colley FC 1975. Eimeria cicaki sp.n. and Isospora thavari sp.n. from the house lizard Gehyra mutilata Boulenger in Malaysia. J Protozool 22: 455-457.

El-Toukhy AAG, Aziz AA, Gawad MAA 1996. Light and electron microscopic studies of Isospora chalchidis (Amoudi, 1989) infecting Chalcides ocellatus in Egypt. J Egypt Soc Parasitol 26: 79-91.

Finkelman S, Paperna I 1994a. The endogenous development of three new intranuclear species of Isospora (Apicomplexa: Eimeriidae) from agamid lizards. Syst Parasitol 27: 213-226.

Finkelman S, Paperna I 1994b. The endogenous development of two new species of Isospora (Apicomplexa: Eimeriidae) from skinks. Syst Parasitol 27: 227-235.

Finkelman S, Paperna I 1995. The endogenous devel- opment of two new species of Isospora Schneider, 1881 (Apicomplexa: Eimeriidae) from Thai geckoes. Syst Parasitol 30: 213-221.

Lainson R, Paperna I 1999. Some coccidia from the gall bladder and intestine of the teiid lizard Ameiva ameiva and the gecko Hemidactylus mabouia in north Brazil. Parasite, in press.

Levine ND 1988. The Protozoan Phylum Apicomplexa, p. 180-188, Vol. I, CRC Press, Inc., Boca Raton, Florida.

Lom J, Dykovà I 1982. Some marine fish coccidia of the genera Eimeria Schneider, Epieimeria Dykovà and Lom and Goussia Labb. J Fish Dis 5: 309-321.

Matuschka FR 1989. Isospora viridanae n.sp., an intranuclear coccidian parasite from the Canarian skink, Chalcides viridanus (Lacertilia: Scincidae). J Protozool 36:274-279.

Modrý D, Koudela B 1995. Description of Isospora jaracimrmani n.sp. (Apicomplexa: Eimeriidae) from the Yemen chameleon Chamaeleo calyptralus (Sauria: Chamaeleonidae). Folia Parasitol, Praha 42: 313-316.

Modrý D, Koudela B, Volf J 1997. Four new species of Isospora Schneider, 1881 (Apicomplexa: Eimeriidae) from reptiles from the islands of Seychelles. Syst Parasitol 37: 73-78.

Mohamed HA, Molyneux DH 1990. Developmental stages of Cyclospora talpae in the liver and bile duct of the mole (Talpa europaea). Parasitology 101: $345-350$

Noller W 1923. Zur kenntnis einem nierencoccids. Der entwicklungskreis des coccids der Waserfroschniere (Isospora lieberkuhni). Arch Protistenkd 47: 101108.

Paperna I, Landsberg JH 1989. Description and taxonomic discussion of eimerian coccidia from African and Levantine geckoes. S Afr Zool 24: 345-355.

Ray HN, Das Gupta M 1937. Isospora knowlesi n.sp. (Coccidia) from the intestine of a lizard, Hemidactylus flaviviridis (Ruppell). Arch Protistenkd 88: 269-274.

Rogier E, Colley F 1976. Description d'Isospora caryophila n.sp., parasite d'un agamidé de Malaisie Péninsulaire. Protistologica 12: 369-373.

Upton SJ, McAllister CT, Trauth SE 1991a. Two new species of Coccidia (Apicomplexa:Eimeriidae) from Eumeces fasciatus (Sauria: Scincidae) in Arkansas. Can J Zool 69: 2028-2030.

Upton SJ, Hanley K, Case TJ, McAllister CT 1991b. Description of Isospora schlegeli sp. nov. (Apicomplexa: Eimeriidae) from gekkonid lizards in the South Pacific. Can J Zool 69: 3108-3110.

Upton SJ, Freed PS, Burdick DA 1992. Description of the oocysts of three new species of coccidia (Apicomplexa: Eimeriidae) from lizards in Namibia. Syst Parasitol 22: 33-37. 